\title{
Is portal vein thrombosis still a contraindication for liver transplantation? A single-institute's 5-year experience and literature review
}

This article was published in the following Dove Press journal:

Transplant Research and Risk Management

18 November 2016

Number of times this article has been viewed

\section{S Ghazwani \\ F Panaro \\ F Navarro}

Department of Transplant Unit, Saint Eloi University Hospital, University of Montpellier, Montpellier, France
Correspondence: F Panaro

Department of Transplant Unit, Saint Eloi University Hospital, University of Montpellier, 80, Avenue Augustin Fliche, 34295-Montpellier, Cedex 5, France

Tel +330467336733

Fax +330467337623

Email f-panaro@chu-montpellier.fr
Background/purpose: Portal vein thrombosis (PVT) is a common problem in candidates for liver transplantation (LT). PVT is a well-recognized complication of patients with end-stage liver disease and its incidence ranges from $2 \%$ to $26 \%$. The total PVT still represents an absolute contraindication for an LT. Various techniques of PV revascularization have been proposed; however, the results are far from optimal.

Objective: The aim of this article is to report our experience in LT with PVT and to analyze the latest literature in this field.

Materials and methods: In the past 5 years, 317 LTs were performed in 317 patients. Twentyone (6.6\%) of them had a PVT (19 partial and two total).

Results: During transplantation, a total thrombectomy was performed in 13 cases and a partial thrombectomy in the remaining six patients. In case of total thrombectomy, a left renovascular revascularization was performed in one case and a left gastric vein revascularization in the other. No cases of PVT recurrence were reported in the early follow-up.

Conclusion: PVT no longer represent an absolute contraindication for an LT.

Keywords: reno-portal anastomosis, portal vein thrombosis, nonanatomical revascularization

\section{Introduction}

Portal vein thrombosis (PVT) is a form of venous thrombosis disease, which affects the hepatic portal vein and can lead to portal hypertension and reduction in the blood supply to the liver. It is thought to be associated with increased resistance to the portal flow from architectural changes in liver tissue associated with cirrhosis. It may be associated with acquired or inherited abnormalities of coagulation and is also commonly seen in the cases of cirrhosis and hepatocellular carcinoma and is generally associated with a poor prognosis. ${ }^{1}$ PVT is a common problem in candidates for liver transplantation (LT) and is considered a problem of patients with end-stage liver disease, with its incidence ranging from $2 \%$ to $26 \%$. $^{2}$ In the initial era of LT, PVT was considered as an absolute contraindication. ${ }^{3}$ Hence, various techniques of PV revascularization during LT have been proposed. However, the results are far from optimal. ${ }^{4}$ Shaw et al reported the first successful LT in a patient with PVT in $1985 .^{5}$ The review that have been reported so far suggests that, independent of the Model for End-Stage Liver Disease (MELD) score, pretransplant PVT may be associated with a 50\% increase in 1-year mortality risk posttransplant. ${ }^{6}$ Mortality varies according to the extension of the thrombus and the surgical procedure. In patients with PVT (whether PVT is partial or complete), when end-to-end portal anastomosis is performed, the results are similar to those in patients without PVT. 
One- and 5-year survival ranges from $84 \%$ to $86 \%$ and from $65 \%$ to $80 \%$, respectively. ${ }^{7-9}$ Based on the literature, it is concluded that the ideal technique to overcome PVT during LTs is still controversial. Short-term follow-up results are promising; however, long-term results are still unknown. ${ }^{10}$

\section{Objective}

The aim of this article was to report our experience in LT with PVT and to analyze the latest literature in this field. The patients whose cases are reported in this paper provided written informed consent to publish their data and images.

\section{Materials and methods Study population}

During the previous 5 years, 317 LTs were performed on 317 patients. Milan criteria were adopted in all the patients. Of the 317 patients, 21 (6.6\%) of them had a PVT (19 partial and two total). In all the cases, the diagnosis of PVT was made preoperatively with imaging and confirmed perioperatively. All the patients underwent a computed tomography (CT) scan before transplantation. Medical and radiological interventions were not applicable because of the chronic behavior of the thrombus and cavernoma formation.

\section{Surgical technique}

In the case of partial PVT, it was decided to perform a thrombectomy. The thrombus was dissected from the intima of the vein with a blind dissection. Eversion thrombectomy is the most commonly used technique for a partial PVT and sometimes complete PVT and a segmental thrombosis localized to the portal vein itself. If the thrombosis was more extensive, invading the main superior mesenteric vein, a venous graft was anastomosed to the distal superior mesenteric vein and brought up through the mesocolon. ${ }^{11}$ The vascular clamp was placed at the spleno-mesenteric convergence. After the thrombectomy, a blood flush was performed in order to remove residual blood clots and to analyze the flow. The thrombus was sent to the histology. This phase was performed before PV anastomosis. The patient underwent Doppler ultrasound every day during the first week and twice weekly thereafter during the first month. A CT scan was routinely performed 15 days after LT. The heparin IV was started on postoperative day (POD) 1 during the first 2 weeks if the hemostatic parameters allowed it (prothrombin time [PT] $>50 \%$, platelets $>50,000$ ). If a partial PVT was still identified in a CT scan, po anti-vitamin $\mathrm{K}$ drug (Fluindione) was started in order to reach an optimal value of international normalized ratio (INR) (2-3) to treat uncomplicated venous thromboembolic disease.

\section{Results}

The mean MELD score of the patients with PVT was 19 (range: 12-41). Eleven had a hepatocellular carcinoma, six had hepatitis $\mathrm{C}$ cirrhosis, two had alcoholic cirrhosis, one had a polyadenome, and one had a regenerative nodular hyperplasia. The mean thrombectomy time was 11 minutes (range: 9-18 minutes). The thrombus histologic analysis revealed a cancer in only one case (the patients had seven hepatocellular carcinoma nodules at the definitive histology). The mean bleeding during the portal thrombectomy was $400 \mathrm{~mL}$ (range: 210-700 mL). The portal vein anastomosis was performed with two running 6/0 polypropylene suture with growth factor to avoid the anastomotic stenosis. All patients had a postoperative low dose of heparin IV. The CT scan revealed a residual PVT in six cases (four at the superior mesenteric vein [SMV] and two at the splenic vein [SV] level). In these six patients, oral anti-vitamin $\mathrm{K}$ drug (Fluindione) was started and close monitoring was required. Three patients required retransplantation because of sepsis. The two cases with total PVT (tPVT) are described separately in the following sections below. At mean follow-up of 26 months, the liver function tests (LFTs) were good in all patients.

\section{Case I}

A 26-year-old male presented with hepatic polyadenome, which was followed by liver segmentectomy of segment VII associated with atypic resection of segment III. Complementary right hepatectomy was successfully performed to treat the appearance of new hepatic nodules. Other nodules appeared with marked increase in their sizes over which LT mandate from cadaveric donor. Intraoperatively, insufficient portal vein flow because of the presence of a huge PVT was detected, which contraindicates a standard anastomosis. For revascularization, a left reno-portal anastomosis was performed (left renal vein [RV] and portal vein $[\mathrm{PV}]$ are well matched and coaxial venous structures); with good postoperative flow (Figure 1). A CT scan at POD 7 confirmed patency of the anastomosis (Figure 2). The patient was discharged at POD 28 with good liver function (Table 1).

\section{Case 2}

A 36-year-old male presented with regenerative nodular hyperplasia secondary to agenesis of the portal vein complicated by portal hypertension, abscess, ischemic cholangitis, and septic shock with acute renal failure. Emergency LT was performed from a cadaveric donor. Intraoperatively, blood flow by portal vein was insufficient because of the presence of PVT, which contraindicates a standard anastomosis. 

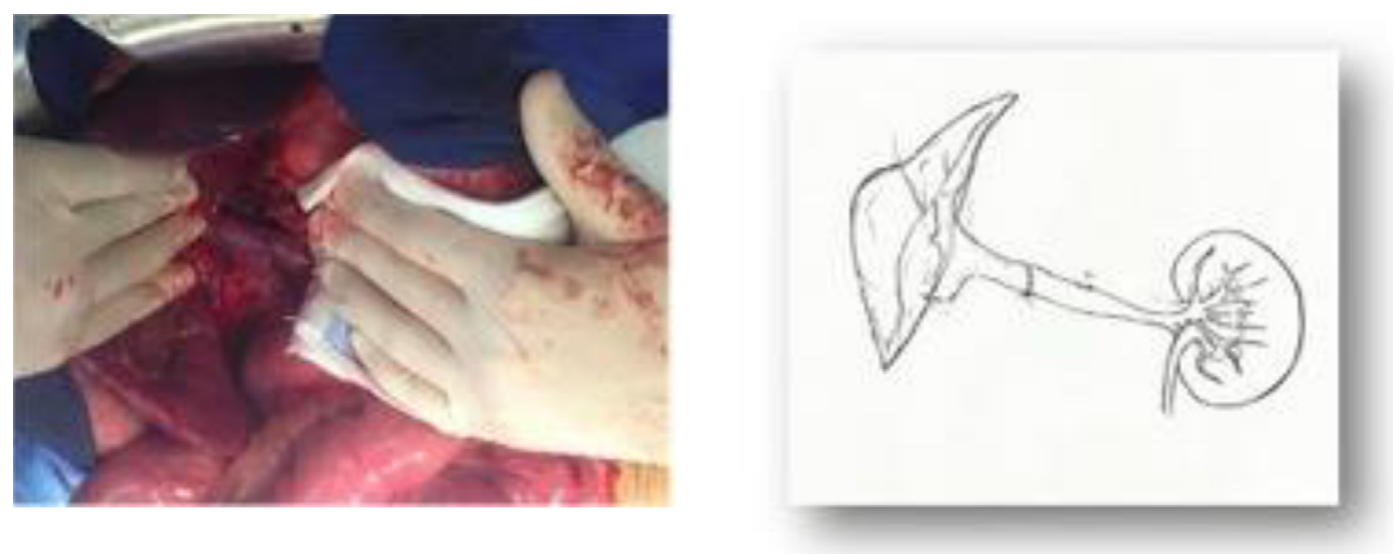

Figure I Intraoperative view of the porto-left renal vein anastomosis (left) and schema of the vascular reconstruction (right) in Case I.

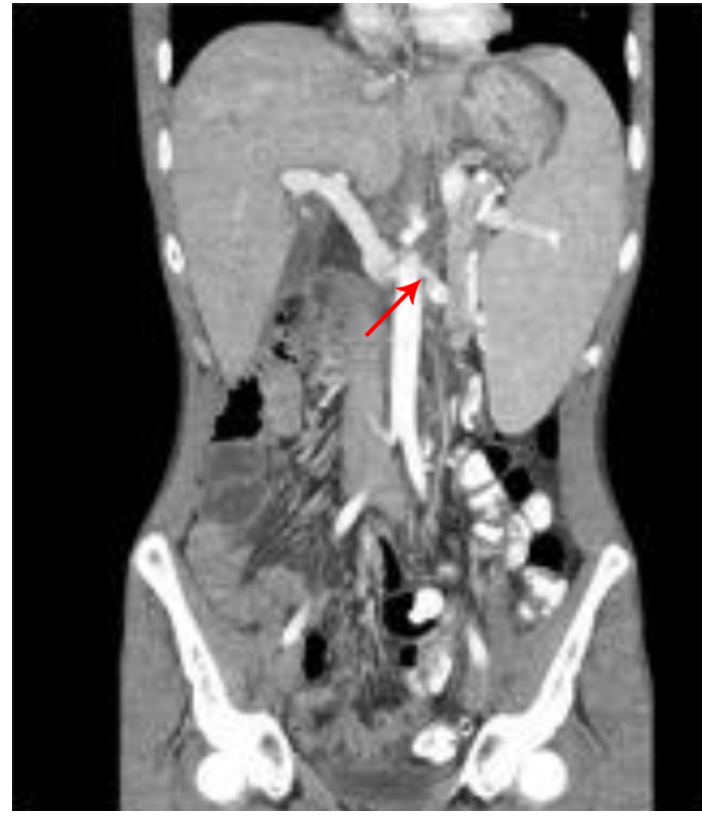

Figure 2 CT scan performed 2 months postoperative.

Note: Abdominal CT scan of Case I showed the reno-portal vein anastomosis (arrow).
Because of this, a portal revascularization of the portal vein was achieved anastomosing the graft portal vein with the left gastric vein with satisfactory postoperative flow (Figure 3). A CT scan at POD 7 confirmed patency of the anastomosis (Figure 4). The patient was discharged at POD 24 with good liver function (Table 1).

\section{Discussion}

LT is now an accepted and efficient therapy for end-stage liver disease. PVT is a complication of chronic liver disease that occurs in $\sim 5 \%-15 \%$ of these patients. ${ }^{12}$ It occurs in the general population at $\sim 1 \%$ and may be caused by various conditions including cirrhosis, cancer, myeloproliferative diseases, inflammation, and abdominal infection, among others. ${ }^{13}$ PVT used to be a contraindication to LT until quite recently. Rapid progress in the surgical technique in the last few years has demonstrated that most patients with PVT can be safely and successfully transplanted. ${ }^{14}$ Considering cirrhotic patients with worsening liver function (expressed by Child-Pugh score), it may occur in up to $26 \% .{ }^{15}$ In patients who are being prepared for LT, it might affect between $5 \%$ and $15 \%{ }^{16,17}$ When PVT was encountered during a surgery

Table I Liver function tests after I month

\begin{tabular}{|c|c|c|c|c|c|}
\hline \multicolumn{3}{|l|}{ Case I } & \multicolumn{3}{|l|}{ Case 2} \\
\hline Element & Result & Normal value & Element & Result & Normal value \\
\hline Albumin & $47 \mathrm{~g} / \mathrm{L}$ & $35-52 \mathrm{~g} / \mathrm{L}$ & Albumin & $38 \mathrm{~g} / \mathrm{L}$ & $35-50 \mathrm{~g} / \mathrm{L}$ \\
\hline Total bilirubin & $13 \mathrm{mmol} / \mathrm{L}$ & $5.1-17 \mathrm{mmol} / \mathrm{L}$ & Total bilirubin & $14 \mathrm{mmol} / \mathrm{L}$ & $5.1-17 \mathrm{mmol} / \mathrm{L}$ \\
\hline PT & 64 seconds & II-13 seconds & PT & 71 seconds & II-I3 seconds \\
\hline AST & $20 \mathrm{U} / \mathrm{L}$ & $0-35 \mathrm{U} / \mathrm{L}$ & AST & $24 \mathrm{U} / \mathrm{L}$ & $0-35 \mathrm{U} / \mathrm{L}$ \\
\hline ALT & $50 \mathrm{U} / \mathrm{L}$ & $0-35 U / L$ & $\mathrm{ALT}$ & $92 \mathrm{U} / \mathrm{L}$ & $0-35 \mathrm{U} / \mathrm{L}$ \\
\hline GGT & $86 \mathrm{U} / \mathrm{L}$ & 8-78 U/L & GGT & $36 \mathrm{U} / \mathrm{L}$ & 8-78 U/L \\
\hline ALP & $159 \mathrm{U} / \mathrm{L}$ & $36-92 \mathrm{U} / \mathrm{L}$ & ALP & $63 \mathrm{U} / \mathrm{L}$ & $36-92 \mathrm{U} / \mathrm{L}$ \\
\hline
\end{tabular}

Notes: Case I: portal-left renal vein anastomosis. Case 2: portal-left gastric vein anastomosis.

Abbreviations: PT, prothrombin time; AST, aspartic aminotransferase; ALT, alanine aminotransferase; GGT, gammaglutamyltransferase; ALP, alkaline phosphatase. 

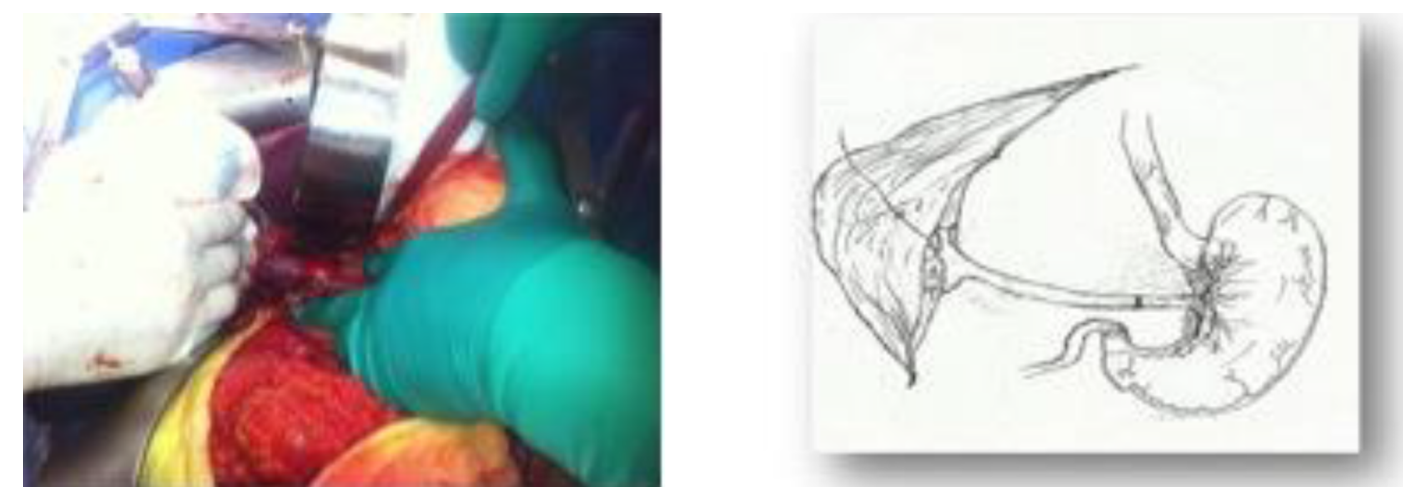

Figure 3 Intraoperative view of the porto-left gastric vein anastomosis (left) and schema of the vascular reconstruction (right) in Case 2.

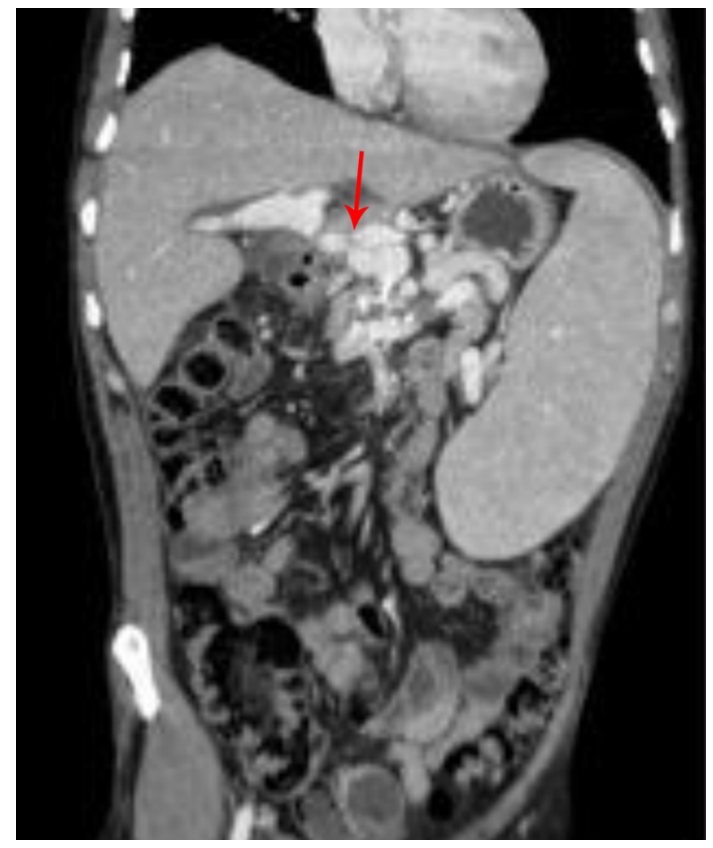

Figure $4 \mathrm{CT}$ scan control done in 2 months postoperative. Note: Abdominal CT scan of Case 2 showed a left gastric-portal vein anastomosis (arrow).

in its various grades, often due to low sensitivity of tests performed preoperatively, the surgeon is faced with a condition in which various surgical strategies may need to be used: thrombectomy, use of graft (autologous or heterologous), anastomosis with collateral vessels to bypass some obstruction, or a cavoportal hemitransposition will enable a successful LT. ${ }^{17-19}$ However, the short-term outcome of these patients is poor with a high morbidity and mortality rate. These advances in surgical techniques of LT have become feasible in some patients with PVT. ${ }^{18,20}$ A number of surgical approaches have been developed to sustain graft viability in cases with PVT-related insufficient portal flow. These approaches include eversion thrombo-endo-venectomy, ligation of collateral splanchnic veins, venous grafting between graft portal vein and recipient superior mesenteric vein, anastomosis with left gastric or gastroepiploic veins, portal arterialization, combined liver-intestine transplantation, cavoportal anastomosis, and end-to-end renoportal anastomosis (RPA) ${ }^{18,20}$ (Table 2). In our experience in the case of partial PVT, an eversion thrombo-endo-venectomy was feasible and efficient to remove the thrombus. Moreover, in case of tPVT, the procedure was to anastomose the graft portal vein with the recipient left renal vein. RPA has the advantage that left $\mathrm{RV}$ and PV are well matched and coaxial venous structures; moreover, the physiological retrohepatic inferior vena cava (IVC) flow, which is devoided only from the left renal venous inflow, remains preserved. ${ }^{21,22}$ In the other total PVT case, anastomosis with the left gastric vein was feasible and efficient too. In early follow-up, there was no liver atrophy presuming the systemic circulation of hepatotropic factors through the meso-caval shunts. Good outcome and satisfactory improvement of portal flow and good recovery of liver function tests in all transplant patients were observed. In the literature, a review of 23 cases published by Selvaggi et al of cavoportal hemitransposition, the global survival was $60 \%$ in a year and $38 \%$ in 3 years, and 9.3 years being the more prolonged survival. ${ }^{23}$ Seven patients presented gastrointestinal bleeding postoperatively, and six developed thrombosis of vena cava. Ascites was observed in almost all the patients, and renal dysfunction was a common event after the first month of transplant. ${ }^{23}$ Pan et al had experience of LT with IPVT in six patients, where in three cases, it was possible to remove the thrombus successfully and two others were submitted to anastomosis with the renal vein and one to cavoportal hemitransposition. ${ }^{24}$ The intra-hospital mortality was $33.33 \%$, two being deaths associated with hepatic failure. The necessity of transfusion was higher in a group with PVT than without PVT $(9.32 \pm 3.12 \mathrm{U}$ and $6.02 \pm 2.40$ $\mathrm{U}$, respectively; $P<0.01$ ). The actuarial survival of 1 year was similar for patients with and without PVT $(86.56 \%$ and $89.40 \%$, respectively; $P>0.05){ }^{24}$ In a meta-analysis study, Paskonis et a $\mathrm{l}^{10}$ compared 15 publications reporting clinical experience with hemitransposition cavoportal or RPA. The 
Table 2 Reported series of literature for outcomes of liver transplant with PVT (within the last 5 years)

\begin{tabular}{|c|c|c|c|c|c|}
\hline Authors & Year & Journal & Number of cases & Results & Recipient outcome \\
\hline Matsumoto et $\mathrm{a}^{28}$ & 2013 & Journal of Surgery Today & $\mathrm{I}$ & Satisfactory & Minor hyperbilirubinemia \\
\hline Akbulut et $\mathrm{al}^{29}$ & 2012 & Journal of Transplant International & I & Satisfactory & Alive free of complications \\
\hline González-Pinto et al ${ }^{18}$ & 2009 & $\begin{array}{l}\text { Journal of Transplantation } \\
\text { Proceedings }\end{array}$ & I & Satisfactory & Alive free of complications \\
\hline Marubashi et a $\left.\right|^{30}$ & 2005 & Transplantation & 3 & $\begin{array}{l}\text { Satisfactory improvement } \\
\text { postoperative }\end{array}$ & $\begin{array}{l}\text { Alive with normal graft } \\
\text { functions }\end{array}$ \\
\hline Kato et $\mathrm{a}^{21}$ & 2000 & Archive of Surgery & 5 & Normal portal flow & $\begin{array}{l}\text { Survival rate of } 80 \% \text { at } \\
18 \text { months of follow-up }\end{array}$ \\
\hline Azoulay et $\mathrm{al}^{22}$ & 2002 & $\begin{array}{l}\text { Gastorenterologie Clinique et } \\
\text { Biologique }\end{array}$ & 8 & $\begin{array}{l}3 \text { died at } 3 \text { and } 6 \text { months } \\
\text { postoperation } \\
3 \text { had } \mathrm{PH}\end{array}$ & $\begin{array}{l}\text { At median } F / U \text { of } 9 \text { months } \\
5 / 8 \text { patients are alive with } \\
\text { normal LFT }\end{array}$ \\
\hline Miyamoto et $\mathrm{al}^{31}$ & 2003 & Journal of Transplantation & I & $\begin{array}{l}\text { Satisfactory postoperative } \\
\text { course. }\end{array}$ & $\begin{array}{l}\text { Alive without } \\
\text { complications }\end{array}$ \\
\hline
\end{tabular}

Abbreviations: PVT, portal vein thrombosis; F/U, follow-up; PH, portal hypertension; LFT, liver function tests.

main complications observed were ascites, renal dysfunction, and digestive hemorrhage being observed in $41.5 \%, 34 \%$, and $24.5 \%$, respectively. PVT applicant occurred in $11.3 \%$ of patients, $11.3 \%$ developed thrombosis of hepatic artery, $9.4 \%$ presented deep venous thrombosis, and $32 \%$ edema of lower limbs or dorsum. The period of follow-up ranged from 2 to 48 months, with $74 \%$ of patients still alive at the end of the follow-up period. Fourteen died during the follow-up period, eleven submitted to hemitransposition, and three to RPA. ${ }^{10}$

Another technical solution is a liver and intestinal transplantation. Currently, the global survival of multivisceral transplantation overcomes the cavoportal hemitransposition reported by Selvaggi et $\mathrm{a}^{23}$ in $60 \%$ of patients in a year. Studies show survival for 1 year in $\sim 70 \%-80 \%$ of the multivisceral transplant patients. ${ }^{25,26}$ But it is a more complex procedure and of largest cost, with higher incidence of complications, as opportunistic infections, proliferative diseases, and rejection episodes. There are no studies reporting the results of multivisceral transplantation for PVT, but it is likely that the results surpass those related to alternatives for complex thromboses. ${ }^{27}$ It is noted that current literature is missing a comparative review between the strategies and which technique is preferable if tPVT is encountered during LT. Life-long follow-up is mandatory to be able to record the details about the advantages and consequences of atypical revascularization.

\section{Conclusion}

Based on our patients' follow-up and an extensive literature review, in the case of partial PVT, a simple thrombectomy and classic re-anastomosis are the treatments of choice. In the case of tPVT, a nonanatomical portal vein (noncaval) revascularization should be considered, especially in selected patients. Multivesceral transplant has a promising future but requires more study and follow-up of its outcome.

\section{Disclosure}

The authors report no conflicts of interest in this work.

\section{References}

1. Englesbe MJ, Schaubel DE, Cai S, Guidinger MK, Merion RM. Portal vein thrombosis and liver transplant survival benefit. Liver Transpl. 2012;16:999-1005.

2. Lendoire J, Raffin G, Cejas N, et al. Liver transplantation in adult patients with portal vein thrombosis: risk factors, management and outcome. HPB (Oxford). 2007;9(5):352-356.

3. Wu TH, Lin YS, Lee CF, Wu TJ, Yu MC, Chan KM, Lee WC. Clinical analysis and strategy for liver transplantation in patients with pre-existing portal vein thrombosis. Chang Gung Med J. 2011;34(4):426-435.

4. Robles R, Fernández JÁ, Hernández Q, et al. Eversion thromboendovenectomy in organized portal vein thrombosis during liver transplantation. Clin Transplant. 2004;18(1):79-84.

5. Shaw BW Jr, Iwatsuki S, Bran K, Starzl T. Portal vein grafts in hepatic transplantation. Surg Gynecol Obstet. 1985;161(1):66-68.

6. Englesbe MJ, Schaubel DE, Cai S, Guidinger MK, Merion RM. Portal vein thrombosis and liver transplant survival benefit. Liver Transpl. 2010;16:999-1005.

7. Manzanet G, Sanjuán F, Orbis $P$, et al. Liver transplantation in patients with portal vein thrombosis. Liver Transpl. 2001;7:125-131.

8. Molmenti EP, Roodhouse TW, Molmenti H, et al. Thrombendvenectomy for organized portal vein thrombosis at the time of liver transplantation. Ann Surg. 2002;235:292-296.

9. Ravaioli M, Zanello M, Grazi GL, et al. Portal vein thrombosis and liver transplantation: evolution during 10 years of experience at the University of Bologna. Ann Surg. 2011;253:378-384.

10. Paskonis M, Jurgaitis J, Mehrabi A, et al. Surgical strategies for liver transplantation in the case of portal vein thrombosis - current role of cavoportal hemitransposition and renoportal anastomosis. Clin Transpl. 2006;20:551-562.

11. Song S, Kwon CH, Shin M, et al. A new technique for complete portal vein and superior mesenteric vein thrombosis in a liver transplant recipient. Exp Clin Transplant. 2014;12(1):67-70.

12. Nonami T, Yokoyama I, Iwatsuki S, Starzl TE. The incidence of portal vein thrombosis at liver transplantation. Hepatology. 1992;16: 1195-1198.

13. Ögren M, Bergqvist D, Björck M, Acosta S, Eriksson H, Sternby NH. Portal vein thrombosis: prevalence, patient characteristics and lifetime risk a population study base on 23796 consecutive autopsies. World $J$ Gastroenterol. 2006;12(13):2115-2119.

14. Stieber AC, Zetti G, Todo $\mathrm{S}$, et al. The spectrum of portal vein thrombosis in liver transplantation. Ann Surg. 1991;213(3):199-206.

15. Hoekstra J, Janssen HLA. Vascular liver disorders: portal vein thrombosis. Netherlands J Med. 2009;67(2):46-52. 
16. Charco R, Fuster J, Fondevila C, Ferrer F, Mans E, García-Valdecasas JC. Portal vein thrombosis in livertransplantation. Transplant Proc., 2005;37(9):3904-3905.

17. Dumortier J, Czyglik O, Poncet G, Blanchet M-C, Boucaud C, Henry L, Boillot O. Eversion thrombectomy for portal vein thrombosis during liver transplantation. Am J Transpl. 2002;2:934-938.

18. González-Pinto IM, Miyar A, García-Bernardo C, et al. Renoportal anastomosis as a rescue technique in postoperative portal thrombosis in liver transplantation. Transplant Proc. 2009;41:1057.

19. Ramos AP, Reigada CPH, Ataíde EC, et al. Portal vein thrombosis and liver transplantation: long term. Transplant Proc. 2010;42(2):498-501.

20. Bhangui P, Lim C, Salloum C, et al. Caval inflow to the graft for liver transplantation in patients with diffuse portal vein thrombosis: a 12-year experience. Ann Surg. 2011;254(6):1008-1016.

21. Kato T, Levi DM, DeFaria W, Nishida S, Tzakis AG. Liver transplantation with renoportal anastomosis after distal splenorenal shunt. Arch Surg. 2000;135(12):1401-1404.

22. Azoulay D, Adam R, Castaing D, et al. Liver transplantation with cavoportal or renoportal anastomosis: a solution in cases of diffuse portal thrombosis. Gastroenterol Clin Biol. 2002;26(4):325-330.

23. Selvaggi G, Weppler D, Nishida S, Moon J, Levi D, Kato T, Tzakis AG. Ten-year experience in porto-caval hemitransposition for liver transplantation in the presence of portal vein thrombosis. Am J Transplant. 2007;7(2):454-460.
24. Pan C, Shi Y, Zhang JJ, Deng YL, Zheng H, Zhu ZJ, Shen ZY. Singlecenter experience of 253 portal vein thrombosis patients undergoing liver transplantation in China. Transplant Proc. 2009;41(9): 3761-3765.

25. Abu-Elmagd KM, Costa G, Bond GJ, et al. Five hundred intestinal and multivisceral transplantations at a single center: major advances with new challenges. Ann Surg. 2009;250(4):567-581.

26. Vianna RM, Mangus RS, Tector AJ. Current status of small bowel and multivisceral transplantation. Adv Surg. 2008;42:129-150.

27. Pecora RAA, Canedo BF, Andraus W, et al.'Portal vein thrombosis in liver transplantation. ABCD Arq Bras Cir Dig. 2012;25(4):273-278.

28. Matsumoto Y, Ikegami T, Morita K, et al. Renoportal anastomosis in right lobe living donor liver transplantation: report of a case. Surg Today. 2013;43(11):1316-1320.

29. Akbulut S, Kayaalp C, Yilmaz M, Yilmaz S. Auxiliary reno-portal anastomosis in living donor liver transplantation: a technique for recipients with low portal inflow. Transplant Int. 2012;25:e73-e75.

30. Marubashi S, Dono K, Nagano H, et al. Living-donor liver transplantation with renoportal anastomosis for patients with large spontaneous splenorenal shunts. Transplantation. 2005;80(12):1671-1675.

31. Miyamoto A, Kato T, Dono K, et al. Living-related liver transplantation with renoportal anastomosis for a patient with large spontaneous splenorenal collateral. Transplantation. 2003;75(9): 1596-1598.
Transplant Research and Risk Management

\section{Publish your work in this journal}

Transplant Research and Risk Management is an international, peerreviewed open access journal focusing on all aspects of transplantation and risk management to achieve optimal outcomes in the recipient improving survival and quality of life. The manuscript management system is completely online and includes a very quick and fair peer-review system,

\section{Dovepress}

which is all easy to use. Visit http://www.dovepress.com/testimonials.php to read real quotes from published authors. 